\title{
SER E NÃO SER: AS RELAÇÕES HISTÓRICAS ENTRE ARQUIVOLOGIA E CIÊNCIA DA INFORMAÇÃO
}

To be and not to be: the historical relationship between archival science and information science

\author{
Renato Pinto Venancio \\ Universidade Federal de Minas Gerais, Escola de Ciência da Informação. Pesquisador do CNPq 1D, rve- \\ nancio@eci.ufmg.br
}

\begin{abstract}
Resumo
A história das relações entre a arquivologia e a ciência da informação ainda é pouco conhecida. O presente estudo analisa essa questão do ponto de vista histórico, recorrendo ao método compreensivo e comparativo. Para isso foram selecionados dois periódicos: The American Archivist e Arquivo \& Administração. Trata-se de publicações das respectivas associações nacionais de arquivistas dos Estados Unidos e do Brasil. Tais associações são aqui consideradas como protagonistas da institucionalização da arquivologia em seus respectivos países. Nesse sentido, o presente texto identifica a partir de quando e de qual maneira, através de suas publicações oficiais, relações com a ciência da informação foram sendo estabelecidas. Procura-se, dessa maneira, conhecer a especificidade de cada experiência histórica e suas repercussões na configuração dos campos arquivísticos norte-americano e brasileiro.
\end{abstract}

Palavras-chave: Arquivologia; Ciência da Informação; História

\section{Introdução}

A arquivologia é uma ciência da informação? Essa questão polariza autores, conforme revelam levantamentos bibliográficos recentes (Tognoli e Guimarães, 2010; Calderon, 2013, p. 65; Marques, 2013a; Marques e Tognoli, 2016). Há abordagens que consideram a primeira área como uma subárea da segunda, mas há também os que as veem como completamente independentes. No presente texto discutiremos essa questão, mas não a partir de uma abordagem epistemológica. Evitaremos, portanto, discutir se os objetos, métodos e postulados da arquivologia e da ciência da informação são, ou não, convergentes. Nosso objetivo é bem mais restrito, mas nem por isso menos importante. Pretendese desenvolver uma abordagem histórica comparativa a partir de uma perspectiva compreensiva, procedimento teórico, diga-se de passagem, considerado fundador das ciências sociais (Weber, 1992).

De acordo com a perspectiva compreensiva, o que importa é definir a autocompreensão dos atores sociais

\begin{abstract}
The history of the relationship between archival science and information science still remain barely known. The pre-sent study analyzes such issue from a historical perspective by means of a comprehensive and comparative method. In order to accomplish it two journals were chosen: The American Archivist and Arquivo \& Administração. These publications belong to the national archival associations in the United States and in Brazil respectively. Thus, the present article identifies the starting point and the way, through official publications, relationships were established with information science. Therefore, it is aimed to identify the specificities of each historical experience and its impact on the configuration of both American and Brazilian archival fields.
\end{abstract}

Keywords: Archival Science; Information Science; History

envolvidos no fenômeno social estudado. Para isso, selecionamos como fonte dois periódicos: The American Archivist e Arquivo \& Administração. Essas escolhas decorrem do fato de que tanto a primeira quanto a segunda revista serem publicações oficiais das respectivas associações nacionais de arquivologia dos Estados Unidos e do Brasil. Portanto, para além do debate teórico, os textos publicados por esses periódicos adquirem uma importante chancela oficial, seja na aproximação entre áreas, seja na demarcação de campos de conhecimento.

A partir de quando e de qual maneira alguns pesquisadores da área de arquivologia começam a ter interlocução com pesquisadores da ciência da informação ou se reconhecem como parte desse campo? Essa interação foi crescente ou sofreu alterações conjunturais? Abordaremos essas questões recuperando a perspectiva adotada e registrada nos mencionados periódicos ao longo das duas décadas posteriores à primeira menção ao 
termo "ciência da informação". Primeiramente abordaremos a publicação norte-americana, em seguida a brasileira, para então indicarmos as conclusões gerais. Porém, antes de avançarmos nessa direção, são necessárias algumas observações de caráter metodológico.

\section{Observações metodológicas}

O presente estudo não recorre à bibliometria ou a estudos semelhantes. Nossa preocupação, portanto, não diz respeito a identificar a relação do conhecimento produzido na área de arquivologia frente à ciência da informação, nem tampouco identificar citações ou parâmetros semelhantes. Também é importante sublinhar que, no levantamento efetuado, foram focalizadas as ocorrências do termo "information science/ciência da informação" no singular e não "information sciences/ciências da informação" no plural. Tal critério reconhece nesse uso uma opção institucional assumida no Brasil. Embora em 1976, a tabela de áreas do conhecimento do CNPq tenha utilizado a expressão no plural, em 1982 esse uso foi alterado para o singular e os cursos de graduação e pós-graduação, a partir de então, a adotaram (Marques, 2013a, p. 96).

Também, em busca de um critério homogêneo, desconsideramos termos aproximados, como "teoria da informação", "information studies" etc., ou traduções da expressão em outros idiomas (francês, espanhol, etc.). Por outro lado, a ocorrência do termo information science/ciência da informação, em nosso levantamento, pode ocorrer em qualquer parte dos artigos (título, conteúdo, bibliografia, etc.), assim como em qualquer parte do periódico, como, por exemplo, em editoriais, entrevistas ou notas técnicas. Tendo em vista que a base de dados da publicação norte-americana indica apenas a incidência do termo, sem revelar sua frequência, foram consultados os exemplares, um a um, para se conferir a quantificação. O mesmo foi realizado no periódico brasileiro.

\section{The American Archivist}

O periódico The American Archivist surge em 1938 e, desde então, apresenta regularidade, não deixando de lançar novos volumes nem mesmo durante a II Guerra Mundial. Na preparação da comemoração dos dez primeiros anos da revista, Philip Brooks (1947) sublinhou a importância, para seu surgimento, do apoio das sociedades históricas. Nesse sentido, cabe destacar o pioneirismo da American Historical Association. Criada em 1884, essa associação instituiu, 15 anos mais tarde, a Public Archives Commission, com o intuito de conhecer o funcionamento e os acervos custodiados por arquivos públicos norte-americanos. Em 1893, chegou a propor a criação de um arquivo nacional, iniciativa que não é atendida. A partir de 1909, publica relatórios dos diagnósticos feitos pela comissão. Também são impressos manuais de arquivologia, consolidando o que se considerava como boas práticas. Ao mesmo tempo em que isso ocorre, começam a ser realizadas conferências de arquivistas nos congressos anuais da American Historical Association.

Em 1938, é lançado The American Archivist, publicação da Society of American Archivists, criada dois anos antes. Esse periódico também foi fortemente influenciado pelo National Archives Act, de 1934, que instituiu o National Archives. A criação desse órgão, atualmente denominado National Archives and Records Administration (NARA), foi um marco importante, complementado na década seguinte pela Hoover Commission, voltada para o estudo da administração do governo federal norte-americano. Essas iniciativas se refletiram fortemente na revista, que, paralelamente ao tratamento técnico dos acervos históricos, volta-se cada vez mais para os documentos em fase de produção. Em 1940, por exemplo, os primeiros esboços das noções de ciclo de vida (definido como "life history") dos documentos e de procedimentos de avaliação são aí publicados (Brooks, 1940; Leahy, 1940); nessa mesma data, propõe-se uma legislação, visando à criação de uma rede regional de arquivos públicos norte-americanos, assim como à padronização da produção dos registros públicos (pela escolha dos suportes, pela definição dos critérios de cópias autênticas, etc.), prevendo-se, ainda, penalidades aos agentes públicos que destruíssem ou perdessem documentos públicos (The American Archivist, 1940).

Tal preocupação, por sua vez, implicou em alterar a formação dos arquivistas, até então baseada em procedimentos intuitivos. Pode-se mesmo afirmar que um dos primeiros atos da Society of American Archivists foi criar uma comissão para estudar essa questão. Em 1938, é apresentado um relatório propondo dois tipos de formação: a primeira para profissionais "to responsible positions in 'major municipal, state, and national archives' - were to be candidates for the Ph.D. degree in history"; ao passo que a segunda daria origem a profissionais

[...] to responsible positions in small governmental units, institutions, and private business - were to have the equivalent of a master's degree in history or political science. Their education was to include archival history and practices and seminars on the appraisal of documentary materials (Jones, 1968, p. 136-137).

Em 1938, um curso de história e administração de arquivos começa a ser ministrado na Universidade de Columbia, mas é rapidamente desativado. No ano seguinte tem início outro curso na Universidade de Washington, que prospera e passa a ser regular. As orientações da Society of American Archivists, dessa forma, deram origem ao archivist (arquivista), que atuava em arquivos públicos, paralelamente ao records manager (gestor de documentos), que atuava em repartições públicas e empresas privadas. 
Em grande medida, é possível afirmar que The American Archivist foi um dos principais meios de divulgação da arquivologia contemporânea, voltada não apenas para os arquivos públicos, como também para gestão dos documentos (records manager) nas administrações públicas e privadas, num momento, diga-se de passagem, em que se começa a registrar o desafio de lidar com grandes conjuntos documentais gerados pelos sistemas burocráticos. Embora se questione a respeito da data de criação de procedimentos dessa gestão, também vistos como resultado das rotinas das próprias instituições, inclusive em tempos remotos (Cox, 2000, p.5-6; p. 23-44), não há como negar que a padronização e a transformação deles em saberes acadêmicos dependeram da mediação de publicações especializadas.

Na revista The American Archivist constata-se que, somente em 1965, é feita a primeira referência ao termo information science. Portanto, entre 1938 e 1964, ao longo dos 111 volumes trimestrais lançados, inexiste menção alguma a esse termo. Em parte, isso se explica pelo fato de a ciência da informação ainda não existir ou estar em formação. Conforme observou um pesquisador, a institucionalização dessa área foi tardia, apenas em "1968, o American Documentation Institute, dos Estados Unidos, mudou seu nome para American Society for Information Science, tornando-se a primeira instituição de Ciência da Informação do mundo" (Ávila, 2013, p.2).

Apesar de essa institucionalização ter sido tardia, a ciência da informação, enquanto área do conhecimento, vinha se estruturando bem antes. A expressão data de 1955 (Merriam-Webster Dictionaries, 2017) e o campo foi tributário do desenvolvimento de áreas específicas. A fundamentação desse campo

[...] foi buscada na Teoria Matemática da Comunicação, publicada em 1949, de autoria de Claude Shannon e Warren Weaver. Tal teoria desenvolveu, pela primeira vez, um conceito científico de informação, preparando o terreno para o surgimento de uma disciplina dedicada a esse objeto (Ávila, 2013, p. 09).

Os autores que por essa época publicam no The American Archivist atribuem origens distintas à arquivologia. Em 1939, por exemplo, um texto de Olga P. Palmer debruça-se sobre a bibliografia europeia da área. Para essa autora, a arquivologia era fruto de uma longa evolução que começa no século XVI, quando da formação das chancelarias das monarquias ou das cidadesEstado, até consolidação como campo técnico especializado no século XIX (Palmer, 1939, p. 69-71).

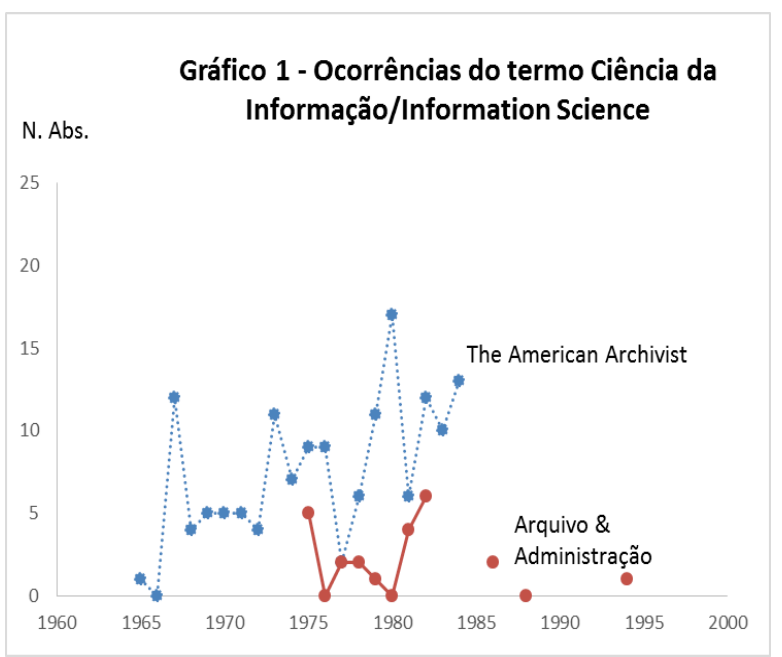

Figura 01: Ocorrência do termo Ciência da Informação/Information Science nos periódicos analisados

Conforme pode ser constatado no Gráfico 1, durante as duas décadas pesquisadas, somente em um ano não há ocorrência do termo. Constata-se também uma tendência ao crescimento do número de referenciações. Ao todo são registradas 149 ocorrências. De acordo com o que mencionamos na metodologia, o termo information science aparece nos mais variados contextos. A análise detida dessas incidências mostra uma presença inicialmente bastante discreta. Por exemplo, no volume de outubro de 1965, ela aparece referida apenas em uma listagem de publicações relativa ao ano anterior:

AMERICAN DOCUMENTATION INSTITUTE. ORGANIZATION OF INFORMATION COMMITTEE. Report for 1962-1963. American documentation, 15:274-288 (Oct.1964). Reports on national trends in "information science" and discusses the evolution of component fields (The American Archivist, 1965, p.530).

No ano seguinte não há menção alguma ao termo. Durante 1967, a expressão retorna, sendo citada em uma resenha. Tratava-se de ambiciosa revisão da literatura, envolvendo dezenas de citações. Nela sublinha-se a vinculação da information science à automação na recuperação da informação, por meio de computadores:

It is hoped that a review of the literature of information science, particularly as relevant to the problems of archives and manuscript repositories, will be continued on a regular basis. Publications of articles and books on the application of computers to nonbook research materials are increasing as the feasibility of approaching the computer in plain language, without excessive coding or mathematical symbolism, is being more widely demonstrated. If computer technology and information science are to have maximum impact on the administration of archives and manuscripts, prompt and thorough communication between sources of technical information and interested repositories must be firmly established and maintained (Fisher and Evans, 1967, p. 348). 
Uma entrevista publicada nesse mesmo volume reforça essa conexão, ao lamentar que a ciência da informação estivesse restrita à teoria computacional:

Information science is logically the most desirable term to cover the entire theory and practice of information handling, but in reality the term has been too much restricted to computer-oriented theory (Wood, 1967, p. 313).

Até 1968, a posição do periódico era a de apenas acompanhar a evolução da nova área e noticiar eventos da recém-criada American Society for Information Science, em

Annual Meeting, American Society for Information Science, Sheraton Columbus Hotel, Columbus, Ohio. Apply to James E. Bryan, Executive Director, 2000 P St. N.W., Washington, D.C. 20036 (The American Archivist, 1968).

Em 1969, o editorial dessa publicação reconhece, porém, as implicações políticas da não integração das áreas, protestando contra uma decisão do governo federal dos Estados Unidos, de não incluir representantes de associações ou agências arquivísticas na National Commission on Library and Information Science (NCLIS). De certa maneira, essa iniciativa foi uma reação à manifestação de um associado: "In his communication Archivist James B. Rhoads suggested that the bill be amended to include archival agencies along with libraries and information sciences" (The American Archivist, 1969, p. 311-312).

Por essa época, notícias bibliográficas indicam pesquisas resultantes da aproximação teórica entre as áreas:

BAHMER, ROBERT H. Archives. In Encyclopedia of library and information science. New York, Marcel Dekker, Inc., 1968. v. 1, p. 515-519.

ALLEN, JOHN C. Item indexing for information coordination in the archival depository. In American Society for Information Science, Proceedings, New York, Greenwood, 1968. P. 95-99 (The American Archivist, 1970, p. 322).

Em 1972, tal aproximação também é registrada em seminários de indexação da National Federation of Science Abstracting and Indexing Services and the American Library Association, vinculada à University of Maryland School of Library and Information Science. (Koucky 1972, p. 147). Nesse mesmo volume noticia-se um livro dedicado à arquivologia, publicado em uma coleção de ciência da informação: J. H. Hodson's The Administration of Archives (International series of monographs in library and information science, vol. 15, Pergamon Press).

Apesar dessas aproximações, em 1973, quase dez anos após a primeira referenciação, a revista não se via como parte integrante da ciência da informação. Exemplo bastante substancial desse posicionamento ocorre por ocasião de um convite feito à Society of American Archivists (SAA), pela American Society for Information Science (ASIS). A primeira associação, em sua resposta ao convite para se integrar como membro da segun- da, deixa bem claro o posicionamento contrário a essa integração, propondo, em vez disso, a formação de comitês conjuntos para tratar de temas afins:

The American Society for Information Science had recently asked the SAA to become a member of its organization. In response to the invitation, the Executive Committee directed Mr. Warner to inform ASIS that the Society was interested in forming joint committees with other professional associations for the purpose of solving problems of common concern. The Society did not believe, however, that membership in another professional organization was particularly useful (The American Archivist,1973, p. 481).

Esse posicionamento foi mantido ao longo da década de 1970. Ele também implicava em não se integrar a associações de biblioteconomia e ou de história. Tratava-se da afirmação de uma identidade própria ao campo arquivístico, embora ações conjuntas fossem bemvistas:

The joint committee with the American Historical Association and the Organization of American Historians has been very successful in this respect and the joint committee with the American Library Association is developing fruitful areas of cooperation. Perhaps similar cooperation with records management associations should be initiated. Our relationship with information science should be explored. For many years we have emphasized how we are different from historians, librarians, and other related professions (Smith, 1974, p. 18).

Além dessa demarcação de território, os primeiros resultados teóricos das aproximações com a ciência da informação são avaliados negativamente. Em 1973, o prestigiado arquivista Frank Evans, membro do conselho da Society of American Archivists e depois seu presidente, resenha o livro de J. H. Hodson, acima referido, que é a primeira publicação da área de arquivos com chancela da International series of monographs in library and information Science. Evans sublinha "inadequacies of this work in a number of particulars". Afirma ainda que o referido livro foi alvo de numerosas outras resenhas negativas e que não deveria ser adotado em cursos de arquivologia. E acrescenta:

"It is particularly unfortunate that this work should be selected to represent our discipline, since in conception and execution it falls far short of an adequate treatment of archives administration in even the author's own country" (Evans, 1973, p. 543-544).

Em 1974, num trabalho de sistematização do vocabulário, os campos e objetos das áreas são apresentados. Nele afirma-se que a ciência da informação trata da "administration of information, its use and transmission, and the application of theories and techniques of information science to create, modify, or improve information handling systems"; enquanto a arquivologia é "that area of general administrative management concerned with achieving economy and efficiency in the creation, use and maintenance, and disposition of records" (Evans and Harrison, 1974, p. 424 e 428). As- 
sim, enquanto a primeira área trata da gestão da informação (information management), a segunda volta-se à gestão de documentos (records management).

Ao longo da década de 1970, essa compreensão não é alterada, inclusive pelo fato de representantes das agências ou das associações arquivísticas não terem sido integrados à National Commission on Library and Information Science (Fleckner, p. 449), situação, digase de passagem, que perdura até 2008, quando essa comissão é desativada (Blumenstein, 2008). De fato, em 1977, registra-se até mesmo uma deliberada defesa da autonomia do campo arquivístico frente à ciência da informação. Hugh Taylor, então membro do Conselho da Society of American Archivists e um ano mais tarde seu presidente, alerta para a "interdisciplinary 'implosion' of knowledge", fazendo uma defesa vigorosa da tradição arquivística frente ao que ele define como o "risco do pulo desesperado no carro alegórico da ciência da informação" ("desperate leap onto the bandwagon of information science"):

There is a new, universal information grammar to be devised and learned. We are dealing here less with techniques than with language and communication circuitry and it is in this context that the craft of the archivist will be practiced. We should thrive in this new environment for we have always worked within a field theory of information derived from the organic nature of archival originals. In the light of this future and because, essentially, we practice a craft, we must seek to preserve our oral tradition of instruction, our empiricism and flexibility, and our holistic approach to the archival scene, so that we enter the whole information field from a position of strength and not as a desperate leap onto the bandwagon of information Science (Taylor, 1977, p. 397).

De acordo com essa visão, a relevância da ciência da informação para a arquivologia dizia respeito à renovação de vocabulário e à exploração da conexão entre linguagem e comunicação, não devendo ter uma função relevante no tratamento técnico dos arquivos.

Em 1977, uma nova discussão, vinculada à ciência da informação, é registrada: como lidar com os documentos criados pelos computadores? Multiplicam-se, então, os autores que discutem a natureza dos documentos eletrônicos. David Bearman (1979, p. 185) é um deles e destaca a importância de se recorrer à literatura de ciência da informação para o entendimento de como esses novos documentos são produzidos. Nessa mesma época também são feitas referências à Unesco e seus programas de harmonização dos currículos dos cursos de arquivologia, biblioteconomia e documentação. É mencionada a School of Information Science, de Rabat, Marrocos (Playchan, 1978, p. 350), instituição criada em 1975, reunindo as áreas acima citadas em uma graduação de ciência da informação, servindo de modelo para os demais países africanos sem condições de criar cursos específicos.
Por outro lado, as instituições universitárias tradicionais também sofrem mudanças. A presença dos documentos eletrônicos nas organizações públicas e privadas gera apreensões. Como lidar com os novos sistemas de informação? Devido a esses e outros questionamentos, mesmo cursos tradicionais de arquivologia sofrem alterações curriculares. No ano de 1981, por exemplo, páginas da revista The American Archivist registram atualizações que estavam ocorrendo na França:

[...] the curriculum of the Ecole des Chartes now does include coursework in archives administration, modern archives, information science, and contemporary history. Nevertheless, the medieval emphasis and the heavy role played by auxiliary sciences is still very evidente (Orr, 1981, p. 30).

A emergência dos documentos eletrônicos é, portanto, o momento de reconhecimento da potencial interação teórica da arquivologia com a ciência da informação e a tecnologia da informação, alterações apresentadas como diálogos interdisciplinares e não como propostas de fusão de áreas.

Essas mudanças, porém, são apenas parte da história. Outra dimensão fundamental consistiu na própria evolução da ciência da informação. Em sua primeira fase, nos anos 1960, essa área ficou restrita aos "problemas técnicos relativos à transmissão de mensagens [...] considerando apenas os aspectos fisicamente observáveis e mensuráveis da "informação"”. Porém, ao longo da década seguinte, o cenário começa a mudar. Embora ainda centrada na "informação científica e tecnológica" (ICT), esse campo também passa a incluir as "práticas informacionais dos cientistas, identificando a importância da comunicação informal". A partir daí uma nova subárea se desenvolve, "utilizando o mesmo instrumental da ICT", que também passa a focar o "ambiente organizacional", inspirando o desenvolvimento dos conceitos e metodologias da gestão dos recursos informacionais e, depois, da gestão do conhecimento. Paralelamente, outra mudança impactante é registrada: surgem os primeiros "estudos de usuários da informação [...] buscando padrões de uso da informação, por meio da medição do acesso físico a determinados documentos ou sistemas de informação", perspectiva reconhecida "como 'comportamento informacional', dedicada aos diversos modelos por meio dos quais se compreendia a totalidade do comportamento humano em relação à informação" (Araújo, 2013, p. 10-13).

Como se vê, a evolução da ciência da informação é rica e complexa. As novas "descobertas" dessa área terão um forte poder de irradiação. A arquivologia não ficou imune e a revista The American Archivist a registrou. Um artigo de 1982 apresenta um programa de pesquisa claramente inspirado na evolução acima traçada:

Automating access to information for intellectual objectives is non-routine and much more complicated than auto- 
mating programs to handle library and archives business functions. To do it well, we need more studies of user behavior and a better understanding of the hierarchical structures into which information is organized, and we must continue to study the ways in which these two features of information science affect each other (Berner, 1982, p.173).

Portanto, é no contexto de estudos de usuários que se observa mais claramente uma aproximação entre as áreas. Mas, paralelamente a essa compreensão, há outras. Em resenha do livro Documentation y documentos, de Vicenta Cortes Alonso, lançado em 1980, avança-se o seguinte comentário:

Rather than rehash old dichotomies between archival and library science, she attempts to distinguish between information science (ciencia de la information), computer science (informatica), and documentation (documentation). Both libraries and archives can fit into the latter category (Ehrenberg et al., 1983 p. 80).

Sob esse ponto de vista, biblioteconomia e arquivologia pertenciam ao campo da documentação. Por outro lado, continua a haver os que defendem uma aproximação cautelosa com a ciência da informação. Na preparação de um programa de congresso científico de 1984, é avançada a seguinte sugestão:

Review the research and development literature in information science for any data that might be relevant to archival exchange systems. David Bearman suggested contracting for someone or some group to undertake such a review, which would involve identifying works in the literature and ongoing projects as well as commenting on their relevance to archivists (The American Archivist, 1984, p. 207).

Ao longo de vinte anos, foram essas as menções substantivas ao termo em questão na The American Archivist. As demais ocorrências dizem respeito a títulos de eventos, periódicos e livros, assim como de instituições e comissões oficiais do governo. Vejamos agora o caso brasileiro.

\section{Arquivo \& Administração}

A revista Arquivo \& Administração surgiu em 1972. Ela consistia em uma iniciativa da Associação dos Arquivistas Brasileiros, fundada no ano anterior, por um grupo de "profissionais de arquivo" preocupados com a institucionalização do campo (Gomes, 2014, p. 109). A simples identificação desses "profissionais de arquivo", em si, constitui um desafio de pesquisa, pois, estrito senso, eles não eram reconhecidos, dada a ausência de cursos superiores na área ou de regulamentação da profissão de arquivista.

Até então, as iniciativas de criação de cursos universitários de arquivologia no Brasil não tinham tido sucesso. Em 1930, por exemplo, quando do estabelecimento da Universidade do Brasil, o Arquivo Nacional pleiteou isso, mas a demanda não foi atendida. A formação, na época, se restringia a treinamentos técnicos ministrados aos funcionários que ingressavam nessa última instituição (Marques, 2013b, p. 171-172). Oito anos mais tarde, com a criação do Departamento Administrativo do Serviço Público (DASP) - fruto da primeira reforma administrativa brasileira, em nível federal, procurando adotar critérios racionais-legais no serviço público (concursos, planos de carreira, planejamento etc.) - alguns servidores recebem apoio para fazer treinamento em instituições arquivísticas internacionais (Santos, 2014, p. 30-34). Geralmente esses profissionais eram formados em biblioteconomia, tendo em vista a existência de cursos superiores nessa área (Castro, 2000, p. 78-79).

Em 1954, com a criação do Instituto Brasileiro de Bibliografia e Documentação (IBBD) surgem congressos especializados promovidos por essa instituição. $\mathrm{Na}$ década seguinte, tais encontros acolhem comunicações sobre o tratamento técnico de documentos de arquivo. O levantamento dos títulos dessas comunicações revela como foi nesses encontros que os procedimentos da arquivologia contemporânea, ou seja, aquela também voltada à gestão de documentos, começaram a ser discutidos entre pesquisadores brasileiros. Eis alguns títulos registrados até 1971: "Os arquivos como fonte fundamental de documentação"; "Documentação na indústria têxtil"; "A documentação administrativa"; "A documentação na Petrobrás"; "Proposta para a organização da documentação legislativa e administrativa brasileira"; "Documentação técnica-administrativa e seu controle com os termos coordenados", etc., etc. (Corujeira, 1977). Esse debate também é estimulado pelas primeiras propostas de pós-graduação em biblioteconomia, que começam a circular a partir de 1967, prevendo currículos com disciplinas sobre "documentação industrial" (sic), assim como de áreas sociais e biomédicas (Castro, 2000, p. 252).

Paralelamente a isso, são registradas mudanças internas ao campo arquivístico. A partir de 1959, a colaboração do DASP com o Arquivo Nacional dá origem ao Curso de Aperfeiçoamento de Arquivo (Marques, 2013b, p. 181), de curta duração - apenas um semestre -, mas que, a partir do ano seguinte, se torna "curso permanente". Ao mesmo tempo são promovidas a vinda de especialistas internacionais e a tradução de importantes obras, como o Manual de Arquivos (1956) e o Documentos públicos e privados: arranjo e descrição (1963), ambos de autoria de Theodore Roosevelt Schellenberg (Santos, 2010, p. 93).

Esses dados mostram alguma atividade na área, mas bem menos do que era necessário. No início da década de 1970, funda-se a Associação dos Arquivistas Brasileiros. O periódico Arquivo \& Administração consistia em seu principal veículo de comunicação. A Associação percebia que, frente ao desenvolvimento internacional, a arquivologia brasileira encontrava-se bastante desarticulada. Daí o esforço de "transformar a ocupa- 
ção com os arquivos numa profissão institucionalizada" (Silva e Orrico, 2014, p. 128), objetivo alcançado até o final da mencionada década, com a regulamentação da profíssão e com a criação de cursos universitários no Rio de Janeiro (UNIRIO, UFF) e Rio Grande do Sul (UFSM) (Marques, 2013b, p. 205).

A escolha da denominação do periódico, em si, é reveladora das escolhas teóricas e metodológicas de seus proponentes. Ao enfatizar o vínculo entre "arquivo" e "administração", sinalizava-se diretamente para a importância da gestão de documentos. Quanto a isso, a revista deu continuidade ao que vinha ocorrendo nos congressos de biblioteconomia e documentação, não só os nacionais como os regionais, aprimorando o debate. Em 1973, no volume 1 da revista, um artigo de Gilda Nunes Pinto, bibliotecária formada em 1958 (Moura et al., 2016, p. 156), tem como título "O arquivo na empresa", onde afirma:

[...] por meio do Arquivo, o empresário poderá orientar o andamento dos negócios, controlar e coordenar as atividades da empresa, analisar os resultados obtidos, situando os documentos na condição de peças vitais para o bom andamento de toda uma estrutura (Pinto, 1973, p. 6).

Além de artigos dessa natureza, os números subsequentes da revista trazem informações sobre as reedições do Curso de Organização de Arquivos de Empresas, promovido pela Associação; também registrando, a partir de 1975, textos sobre funções arquivísticas ainda pouco conhecidas no Brasil, como no artigo "Avaliação e seleção e documentos de arquivo; Problemas e Soluções", de Nilza Teixeira Soares.

O Gráfico 1, conforme vimos, indica as menções à ciência da informação no periódico Arquivo \& Administração. Ao todo são registradas 23 menções nas duas décadas posteriores à 1975, data em que o termo é mencionado pela primeira vez, numa curta nota intitulada "Recado da Redação":

Este primeiro número de 1975 aborda problemas importantes no campo da conscientização da matéria ARQUIVO, como ciência de informação e documentação. Parece que, finalmente, conseguimos despertar para uma nova visão do que seja a missão dos Arquivos (Arquivo \& Administração, 1975a, p. 5).

Portanto, foi somente três anos após o lançamento da revista que a expressão é utilizada, apresentando claramente a arquivologia como ciência da informação. Nos sete primeiros volumes, porém, não há referências a esse tema ou vínculo. Na mesma publicação de 1975 , outra referência ajuda a entender a mudança em curso. Tratava-se da notícia de que a "I REUNIÃO BRASILEIRA DE CIÊNCIA DA INFORMACAO será realizada no Instituto Brasileiro de Bibliografia e Documentação, IBBD, de 15 a 20 de junho de 1975". Ora, nesse evento, o então presidente da Associação dos Arquivistas Brasileiros, José Pedro Pinto Esposel, apresenta uma comunicação defendendo a institucionalização da profissão de arquivista e a criação do sistema nacional de arquivos. O mais interessante, porém, é a seguinte observação que ele faz: "o grupo que está comigo é todo formado por bibliotecárias" (Esposel, 1978, p. 207) - tratava-se de uma alusão a origem sócioprofissional dos membros da diretoria da Associação.

Embora o primeiro presidente fosse bacharel em direito e historiador, também formado no curso permanente do Arquivo Nacional, seu entorno era composto por profissionais de biblioteconomia e documentação. Tanto era assim que sua sucessora, Helena Corrêa Machado, era bibliotecária com experiência à frente da Divisão de Documentação do antigo estado da Guanabara (Santos, 2010 , p. 88). A ascensão dela confunde-se com a primeira menção ao termo ciência da informação nas páginas da revista Arquivo \& Administração. Embora não assinada, a mencionada "Nota da Redação", publicada no início do mandato dessa nova presidente, provavelmente foi por ela redigida, numa referência ao artigo de sua autoria, intitulado "Principais critérios de organização de arquivos", resumindo o conteúdo do curso de organização de arquivos de empresas.

Não se tratava de uma ocorrência isolada. Conforme é sabido, a introdução da ciência da informação no Brasil deve muitíssimo aos bibliotecários documentalistas. A primeira pós-graduação brasileira da área surge em 1970, justamente no Instituto Brasileiro de Bibliografia e Documentação (Pinheiro, 2002, p. 65), que cinco anos mais tarde se transforma em Instituto Brasileiro de Informação em Ciência e Tecnologia (IBICT). No segundo volume lançado em 1975, tal vínculo é reconhecido e ampliado para a arquivologia. Em novo "Recado da Redação", afirma-se que "entre os vários artigos e notícias de grande interesse para nós, destacase o importante artigo do Prof. M. E. Carroli sobre Arquivos e Automação, que dá continuidade a matéria de Arquivística como ciência da informação" (Arquivo \& Administração, 1975b, p. 6). Tal vinculação deve ser entendida como um desdobramento da conexão teórica entre a biblioteconomia e documentação com a ciência da informação. Tanto é assim que, no mesmo ano de 1975, a presidente da associação dos arquivistas reproduz, em um volume da revista, um discurso intitulado “Arquivologistas, bibliotecários e museólogos de mãos dadas", proferido por ocasião do "Congresso de Biblioteconomia e Documentação”. Nele não considera contraditório apresentar, agora, a arquivologia como uma subárea desse último campo:

$\mathrm{Na}$ história das profissões integrantes da área da Documentação, nós os bibliotecários temos a primazia da dianteira. Como uma tradição de formação superior, com uma performance profissional já respeitada, a luta dos bibliotecários pode hoje se dirigir para a otimização da sua participação no desenvolvimento nacional, em ritmo do tropismo para a perfeição, já agora no âmbito da Ciência da Informação. Mercê dessa justa conquista, nós os bibliotecários temos sido, muitas vezes, convocados para militar em outras áreas da Documentação, especialmente da $\mathrm{Ar}$ - 
quivologia e Museologia, que só recentemente adquiriram o direito à Universidade (Machado, 1975, p. 26).

Constata-se, de acordo com essa visão, que a arquivologia é tributária da tradição da documentação. A ciência da informação, por sua, vez representaria um avanço "para a perfeição". Em 1977, outro artigo publicado, fruto de prêmio em concurso de monografias do Arquivo Nacional, reitera esse último vínculo. O título desse texto é bastante revelador da expectativa então existente: "Arquivos: viga mestre da informação". Nele sublinha-se que a ciência da informação não deveria se voltar exclusivamente aos computadores:

Entretanto, verificamos, em que pese todo esse quadro favorável ao avanço da ciência da informação, que se torna mais evidente entre nós a necessidade de formulação das linhas gerais de ação no que respeita a arquivos. Note-se que, de preferência a falar em arquivos, de onde parte qualquer iniciativa para elaboração da informação, na sua fase primária, nossos planejadores se preocuparam mais ao elaborar o II PBDCT [Plano básico de desenvolvimento científico e tecnológico], com a computação, vendo aí a solução para seus problemas mais imediatos, julgando assim melhor servir à ciência, à tecnologia e a administração em si. Esqueceram-se de que, para um controle real dessa informação tão respeitada atualmente, necessário será, antes, a organização das suas bases: os arquivos (Santos, 1977, p. 5).

Outra bibliotecária, já citada anteriormente, retoma essa discussão no ano seguinte, apresentando, inclusive, a genealogia da ciência da informação brasileira:

A documentação e a informatologia (ciência da informação) surgiram da bibliografia, instrumento insuficiente para atender ao elevado número de publicações que, por sua vez, secundou a biblioteconomia, conforme a genealogia estabelecida pelo nosso colega Edson Nery da Fonseca. Somos de opinião que, embora a metodologia arquivística obedeça a princípios próprios e inconfundíveis, as técnicas de documentação e informação são também aplicáveis ao acervo de arquivo. Porém, há que se responsabilizar o arquivista pelas informações de caráter oficial e os bibliotecários pelas demais (Soares, 1978, p. 14).

Independentemente de se aceitar esses postulados, o certo é que a arquivologia contemporânea brasileira, aquela que adota os procedimentos da gestão documental, é divulgada como parte do campo da ciência da informação. As traduções publicadas na revista reforçam esse vínculo:

Nesta definição estão encerradas as diferenças fundamentais entre arquivos e bibliotecas, entre arquivos e documentação e, consequentemente, as diferenças profisssionais entre arquivistas, bibliotecários e documentalistas. As três profissões são parte do que hoje conhecemos como Ciência da Informação (Duchein, 1978, p. 30).

Eventos científicos promovidos, ou com participação da Associação dos Arquivistas Brasileiros, também estimulavam essa compreensão. Em 1981, na sessão solene em homenagem ao dia do arquivista, na Câmara de Vereadores do Rio de Janeiro, a representante da Associação dos Arquivistas Brasileiros afirma:

Necessitamos de uma verdadeira prática de crescimento. Trata-se da nossa área de atuação. O que fazemos é manipular a informação em todos os níveis, e não foi por acaso que surgiu a ciência da informação. O que ela tenta fazer é firmar os elos entre a arquivística, a biblioteconomia, a documentação e a computação [...] (Arquivo \& Administração, 1981, p. 22).

A partir de 1982, nossa pesquisa enfrenta dificuldades, pois a publicação da revista torna-se errática. A crise econômica pela qual o país passava se reflete no financiamento da pesquisa e em sua divulgação. A Associação também enfrenta problemas internos. Até o final dessa década, apenas outros três volumes são lançados. Neles há referências bibliográficas à ciência da informação. Em 1994, último ano de nossa amostragem, a revista retorna, com o volume "15-23", tentando preencher a lacuna de quase uma década de ausência. Nesse volume é publicada a primeira crítica à ciência da informação. De acordo com Ana Maria de Almeida Camargo:

Pressupondo que o significado pleno de cada documento só se evidencia através do vínculo mantido com os outros documentos do mesmo arquivo e que o fundamental é entender o arquivo como conjunto indissolúvel de documentos necessariamente unidos entre si, os defensores mais veementes desta posição chegam a negar, inclusive, que a arquivística seja considerada uma ciência da informação (Camargo, 1994, p. 38).

Como se vê, a autora afirma que somente os "mais veementes $[. .$.$] chegam a negar" à arquivologia o status$ de ciência da informação. Trata-se de crítica bastante velada, sugerindo um ambiente institucional pouco propício a ela. Ao longo de duas décadas, eis a única censura constatada ao entendimento da arquivologia como uma subárea da ciência da informação.

\section{Considerações Finais}

No Gráfico 1, a comparação das curvas mostra uma trajetória não muito discrepante. Em 1977, esses números chegam a coincidir. No entanto, o conteúdo das referências é completamente diferente. Tal constatação bastaria para realçar a especificidade da arquivologia brasileira frente a outras experiências internacionais, interpretação já defendida em outra pesquisa (Marques, 2013b). O argumento de que poderíamos encontrar realidades completamente diferentes, pesquisando outros periódicos, deve, por sua vez, ser contrabalançado pela constatação de que as publicações em foco expressam a visão oficial das respectivas associações nacionais de arquivistas. Portanto, não se trata apenas de um fórum de debates acadêmicos, mas também de chancela e de posicionamento oficial da área.

Nesse sentido, é possível observar que a experiência brasileira é bastante distinta da norte-americana. Nos 
Estados Unidos, a arquivologia se estruturou a partir das associações de pesquisa histórica, mas, nos anos 1930, se afastou delas, criando uma identidade própria, em forte diálogo com as teorias da administração. Portanto, nesse país, a arquivologia se institucionalizou numa fase em que a biblioteconomia e documentação ainda se estruturavam e a ciência da informação não existia. No caso do Brasil, na década de 1970, a arquivologia contou com a experiência prévia da biblioteconomia e documentação, áreas em que a aproximação com a ciência da informação estava em curso, influenciando fortemente o fenômeno aqui estudado.

Em nosso país, portanto, a institucionalização da arquivologia foi tardia. Novas pesquisa podem confirmar até que ponto essas circunstâncias moldaram, no Brasil, os cursos de graduação em arquivologia, assim como podem auxiliar a compreender como, nas agências de financiamento e fomento à pesquisa, se estruturou a vinculação da arquivologia como subárea da ciência da informação, inserindo-a nesses cursos de pósgraduação. Também é possível que essa trajetória explique por que, a partir dos anos 1990, a comunidade brasileira de arquivistas, formada numa tradição que começa duas décadas antes, abraçará tão calorosamente certas publicações portuguesas e canadenses (Jardim, 1998; Medeiros et al., 2010), que defendiam a vinculação acima indicada, embora sem discutir por que as primeiras publicações utilizam a expressão no singular ("ciência da informação"), ao passo que as segundas a empregam no plural ("ciências da informação"). Mas isso é uma outra história!

\section{Notes}

(1) Agradeço a Jânia Martins Ramos pela leitura e comentários. Também agradeço ao Prof. Rogério Melo Araújo por ter disponibilizado cópias dos exemplares da Revista Arquivo \& Administração, não disponíveis na internet ou na Biblioteca da Escola de Ciência da Informação da UFMG.

(2) Em inglês, empregam-se os termos "record" e "document" com significados diferentes, mas isso não é usual no Brasil, daí traduzirmos as duas palavras como "documento".

\section{References}

Araújo, Carlos Alberto Ávila (2013). O que é Ciência da Informação? // Informação \& Informação 19:1 (2013) 01-30.

Arquivo \& Administração (1975a). Recado da Redação. // Arquivo \& Administração 3:1 (1975) 5.

Arquivo \& Administração (1981). Informe. // Arquivo \& Administração 9:1(1981) 18-34.

Arquivo \& Administração (1975b). Recado da Redação. // Arquivo \& Administração 3:2 (1975) 6.

Bearman, David (1979). Automated Access to Archival Information: Assessing Systems. // The American Archivist 42: 2 (1979) 179190.

Berner, Richard (1982). Toward National Archival Priorities: A Suggested Basis for Discussion. // The American Archivist 45:2 (1982) 164-174.
Blumenstein, Lynn (2008). Closing NCLIS Looks Back and Forward. // Library Journal, 2008. http://lj.libraryjournal.com/2008/05/organizations/closing-nclislooks-back-and-forward/ (21-10-2017).

Brooks, P. C (1940). The selection of records for preservation. // The American Archivist 3:4 (1940) 221-234.

Brooks, Philip (1947). The First Decade of the Society of American Archivists. // The American Archivist 10:2 (1947) 115-128.

Calderon, Wilmara Rodrigues (2013). O arquivo e a informação arquivística: da literatura científica à prática pedagógica no Brasil. São Paulo: Cultura Acadêmica, 2013.

Camargo, Ana Maria de Almeida (1994). Arquivo, documento e informação: velhos e novos suportes // Arquivo \& Administração 15:23 (1994) 34-40.

Castro, César Augusto (2000). História da biblioteconomia brasileira: perspectiva histórica. Brasília: Thesaurus Editora, 2000.

Corujeira, Lindaura Alban (1977). Congressos brasileiros de biblioteconomia e documentação: bibliografia. // Revista de Biblioteconomia 5:1 (1977) 317-365.

Cox, Richard J (2000). Closing an era: historical perspectives on modern archives and records management. Santa Barbara: Greenwood Publishing Group, 2000.

Duchein, Michel (1978). O papel da arquivologia na sociedade de hoje. // Arquivo \& Administração 6:3 (1978) 30-36.

Ehrenberg, Ralph et al. (1983). Reviews. // The American Archivist $46: 1$ (1983) 75-89.

Wood, Elizabeth (1967). From the Information Soapbox: Information Handling Dialectically Considered. // The American Archivist 30:2 (1967) 311-320.

Esposel, José Pedro Pinto (1978). A informação-arquivo. // Anais do $1^{\text {a }}$ Reunião brasileira de ciência da informação, 15-20 de julho de 1975. Rio de Janeiro: CNPq/IBICT, 1978.

Evans, Frank (1973). The Administration of Archives. // The American Archivist 36:4 (1973) 543-550.

Evans, Frank; Harrison, Donald (1974). A Basic Glossary for Archivists, Manuscript Curators, and Records Managers. // The American Archivist 37: 3 (1974) 415-518.

Fisher, Barbara; Evans, Frank (1967). Automation, Information, and the Administration of Archives and Manuscript Collections: Bibliographic Review. // The American Archivist 30:2 (1967) 333348 .

Fleckner, John (1976). Cooperation as a Strategy for Archival Institutions. // The American Archivist 39:4 (1976) 447-459.

Gomes, Yuri Queiroz (2014). A Associação dos Arquivistas Brasileiros e o processo de institucionalização da Arquivologia no Brasil: 1971-1978. // Marques, Angela Alves da Cunha et al (orgs). História da Arquivologia no Brasil: instituições, associativismo e produção científica. Rio de Janeiro: AAA/Faperj, 101-122.

Jardim, José Maria (1998). A produção de conhecimento arquivístico: perspectivas internacionais e o caso brasileiro (1990-1995). // Ci. Inf. [online] 27:3 (1998). http://lj.libraryjournal.com/2008/05/organizations/closing-nclislooks-back-and-forward/ (21-10-2017).

Jones, H (1968). Archival Training in American Universities, 193868. // The American Archivist 31:2 (1968) 135-154.

Koucky, Judith (1972). The 35th Annual Meeting of the Society of American Archivists. // The American Archivist 35: 1 (1972) 13148 .

Leahy, Emmett (1940). Reduction of Public Records. // The American Archivist 3:1 (1940) 13-38. 
Machado, Helena Corrêa (1975). Arquivologistas, bibliotecários e museólogos de mãos dadas. // Arquivo \& Administração 3:2 (1975) 26-27.

Marques, Angelica Alves da Cunha (2013a). Os Lugares da Arquivologia no campo da informação. // Ciência da Informação 41:1 (2013) 92-106

Marques, Angelica Alves da Cunha (2013b). A arquivologia brasileira: busca por autonomia cientifica no campo da informação e interlocuções internacionais. Rio de Janeiro: Associação dos Arquivistas Brasileiros, 2013.

Marques, Angelica Alves da Cunha; Tognoli, Natália Bolfarini (2016). Entre a arquivologia e outras disciplinas: promessas de interdisciplinaridade? // Páginas a\&b: arquivos \& bibliotecas 3:6 (2016) 65-83.

Medeiros, Nilcéia Lage et al. (2010). As relações do conhecimento produzido na área de arquivologia com a ciência da informação. // Ci. Inf. 39:2 (2010) 44-53.

Merriam-Webster Dictionaries (2017). https://www.merriamwebster.com/dictionary/information\%20science (21-10-2017).

Moura, Marina Gomes de; Dahás, Sâmia Chantre; Weitzel, Simone da Rocha (orgs.) (2016). Livro dos egressos da escola de biblioteconomia da UNIRIO. Rio de Janeiro: S/ed., 2016.

Orr, William (1981). Archival Training in Europe. // The American Archivist 44:1 (1981) 27-39.

Palmer, Olga P (1939). The history of european archival literature. // The American Archivist 2:2 (1939) 69-85.

Pinheiro, Lena Vania Ribeiro (2002). Gênese da Ciência da Informação ou sinais anunciadores da nova área. // Aquino, Mirian de Albuquerque. (Org.). O campo da Ciência da Informação: gênese, conexões e especificidades. João Pessoa: UFPB, 61-86.

Pinto, Gilda Nunes (1973). O arquivo na empresa. // Arquivo \& Administração 1:1 (1973) 6.

Plavchan, Ronald (1978). The International Scene: News and Abstracts. // The American Archivist 41:3 (1978) 343-354.

Santos, Maria Aparecida dos (1977). Arquivos: viga mestre da informação. // Arquivo \& Administração 5:3 (1977) 05-20.

Santos, Paulo Roberto E. Santos (2010). Arquivística no laboratório: história, teoria e métodos de uma disciplina. Rio de Janeiro: FAPERJ, 2010.

Santos, Paulo Roberto Elian dos (2014). Administração pública, arquivos e documentação no Brasil: a presença do Departamento Administrativo do Serviço Público nas décadas de 1930 a 1950. // Marques, Angela Alves da Cunha et al (orgs). História da Arquivologia no Brasil: instituições, associativismo e produção científica. Rio de Janeiro: AAA/Faperj, 17-48.
Silva, Eliezer Pires da; Orrico, Evelyn Goyannes Dill (2014). Discursos de memória do associativismo arquivístico brasileiro. // Marques, Angela Alves da Cunha et al (orgs). História da Arquivologia no Brasil: instituições, associativismo e produção científica. Rio de Janeiro: AAA/Faperj, 123-142.

Smith, Wilfred (1974). Broad Horizons: Opportunities for Archivists. // The American Archivist 37:1 (1974) 03-14.

Soares, Nilza Teixeira (1978). Arquivos em sistemas nacionais de informação. // Arquivo \& Administração 6:3 (1978) 12-18.

Taylor, Hugh (1977). The Discipline of History and The Education of the Archivist. // The American Archivist 40:4 (1977) 395-402.

The American Archivist (1965). Writings on Archives, Current Records, and Historical Manuscripts: 1964. // The American Archivist 28:4 (1965) 529-623.

The American Archivist (1969). President's Page. // The American Archivist 32: 3 (1969) 271-316.

The American Archivist (1970). Front Matter (Front Cover, Masthead, Table of Contents, From the Editor). // The American Archivist 33:4 (1970) 466-466.

The American Archivist (1973). Writings on Records Management: A Select List. // The American Archivist 36:3 (1973) 367-482.

The American Archivist (1984). Technical Notes. // The American Archivist 47:2 (1984) 193-218.

The American Archivist (1940). The Proposed Uniform State Public Records Act. // The American Archivist 3:2 107-130

Tognoli, Natália Bolfarini; Guimarães, José Augusto Chaves (2010). Ciencia de la información y archivística: un diálogo a partir de la información registrada. // Ibersid: revista de sistemas de información y documentación 4:1 (2010) 131-136.

Weber, Max (1992). A "objetividade" do conhecimento na ciência social e na ciência política (1904). // Metodologia das ciências sociais. Parte 1. São Paulo: Ed. da Unicamp/Cortez, 1992, p. $107-154$.

Copyright: (c) 2017 Venâncio. This is an open-access article distributed under the terms of the Creative Commons CC Attribution-ShareAlike (CC BY-SA), which permits use, distribution, and reproduction in any medium, under the identical terms, and provided the original author and source are credited. 